\title{
SCHOOL EDUCATION IN A VIRTUAL SPACE: BETWEEN DAMAGE CONTROL, SCHOOL DEVELOPMENT AND INNOVATION
}

\author{
Annika Wilmers ${ }^{1}$ and Bettina Waffner ${ }^{2}$ \\ ${ }^{1}$ Leibniz. Institute for Research and Information in Education \\ Rostocker Str. 6, 60323 Frankfurt am Main, Germany \\ ${ }^{2}$ University of Duisburg-Essen, Chair of Educational Technology and Knowledge Management \\ Universitätsstr. 2, 45117 Essen, Germany
}

\begin{abstract}
This contribution presents current findings on the conditions of success and challenges to school-related learning with digital media. A particular focus is placed on teachers and school leaders, because these two groups take a key position in shaping education in a digital world. While we focus on examples taken from the German school context, we are nevertheless able to compare them with international research findings and to analyze similarities as well as disparities between different education systems.
\end{abstract}

\section{KEYWORDS}

Critical Review, School Development, Digitalization, Educational Technology

\section{BODY OF PAPER}

The Covid-19 pandemic has led to school closures in nearly all countries worldwide (Gouëdard, Pont, Viennet, 2020). Digital media have replaced classic school settings, to enable remote teaching as quickly as possible in this exceptional situation. This emergency remote teaching, however, distorts the perspective on potentials and tension fields of integrating digital media into teaching practice. The pandemic-related handling of digitizing in school education has thus entailed a risen awareness of potentials of virtual ways of contacting, providing learning resources, and submitting tasks. At the same time, this will not lead to an orientation and societal agreement on what schools might look like in a post-pandemic digital world. The characteristic feature will probably not be to expand distance learning. Rather, the understanding of education will change in a world that is permeated by digital technology and our actions are closely linked to digital technology. Education in the digital world will be less about mastering technology. It also points beyond the present to a future in which technology is not to be understood as a tool but rather as a (co-)actor (Kerres, 2021).

Against this background media integration can serve as a catalyst for school development (Sipilä, 2014) and it can mean long-term change reaching far beyond the current global crisis. For example, shifting learning to individual learning environments can also be discussed in terms of a chance for individual learning concepts (Burow, 2018; Zhao, 2020). The current debate in Germany rather focuses on existing deficits of digitizing and an acerbation of existing inequalities in education. Since the outbreak of the pandemic, respective political measures have thus targeted a removal of present deficiencies, such as is illustrated by an agreement on the loan of electronic devices to teachers (BMBF, 2021). At the school level, inequalities relate to differences in learning support due to technical and administrative conditions, teacher competencies and the existing degree of integration of digital media into the learning context (e.g. Bremm \& Racherbäumer, 2021; LIfBi, 2020).

Against this background, we present current findings on the conditions of success and challenges to school-related learning with digital media. We can assume that we are facing a paradigm shift. Schools will have to understand (disruptive) change as an integral part of school development and create various possible solutions in the change process, resulting in multiple future scenarios (Rolff \& Thünken, 2020). A particular 
focus is placed on teachers and school leaders, because these two groups take a key position in shaping education in a digital world.

The analysis is based on results from the project "Digitizing in education" (Digi-EBF) by the Federal Ministry of Education and Research. Subject to a series of reviews, the state of research on relevant actors as well as organizational and socio-political structures of the education system is assessed and analyzed together with content contexts of hybrid learning arrangements for five educational sectors. Methodologically, the project links up to critical review procedures. Critical reviews typically focus on identifying conceptual components of the included literature and often contribute to either existing models in the field or support the development of new models (Grant \& Booth, 2009; Booth, Sutton \& Papaioannou, 2016). The research synthesis enables an outline and discussion of current developments as well as identification of research needs and future directions. The following findings are based on two such critical reviews focusing on the school sector, for which a systematic and comprehensive literature search was conducted in selected German and international databases that were identified as highly relevant for digitization in education nationally and internationally such as FIS Bildung (largest German database for education research), ERIC, Web of Science - Social Citation Index, ERC and LearnTechLib. A total of 4936 studies was screened in a multistep process. As a result from the coding process 125 (from the years 2010-2019, review 1) respectively 56 (2016-2020, review 2) studies published in German and English were selected for an analysis and research synthesis (for a description of the method and lists of all included studies, see Wilmers, Anda, Keller \& Rittberger, 2020 and Wilmers, Achenbach, Keller, 2021 in print).

When introducing digital media to teaching practice, this can be done in different ways. The scope ranges from use as a medium of presentation and substitute of classical analogue media, to support and modernize traditional lesson formats, and pedagogical instructional innovations that lead to more self-governed types of learning and knowledge acquisition due to cooperative learning. In this case, learning at school will change and pay tribute to an increasingly digitized, global world.

A focus of current research lies in the question which factors benefit an implementation of digital media in instructional practice. In this regard, little attention has so far been paid to the teachers' use of digital media and whether by the integration of such media, implications are evident for instructional formats and pedagogical practice. There is empirical evidence that digital media are already well established in the teachers' professional lives, as communication and presentation tools. However, this is rarely guided by (media)pedagogical goals, and digital media are rather regarded as tools than being an integral part of learning. This corresponds with the finding that most teachers take a rather positive stance regarding computers and smartboards. On the other hand, they are skeptical regarding the Worldwide Web or social networks, such as Twitter and Facebook as instruments reaching beyond the classroom. This seems to explain why moderate to sound technical-instrumental user competencies of teachers do exist, while a development and implementation of digitally based didactic pedagogical lesson formats is comparatively rare. These findings have far-reaching implications for school development in the digital world. They show that the digitalisation push by the Covid-19 pandemic (Kleinert, Bächmann, Schulz, Vicari \& Ehlert, 2021) does not automatically lead to media integration that adapts teaching practices to the digital world. In order to create schools in the digital world, it is necessary to deal with pedagogical-didactic possibilities of using digital media in the classroom, further training for teachers, suitable technical equipment and leadership.

If and how digital media are used in instructional practice is highly dependent on individual teachers. In this regard, it is especially important to assess competencies and competence acquisition in terms of initial and further training. A focus on so-called "new digital competencies" that immediately emerge from handling technical devices disregards the fact that "digitizing permeates traditional teaching practice" (Kerres, 2020, p. 8). With respect to current research findings, we can thus observe a need for a shift from a technical to a pedagogical focus in the discussion of competencies. At the same time, the discussion remains at the point of identifying additional competencies that go beyond those of a subject and its instructional design.

In summary, five synthesis statements are identifiable: (1) the Digital is well established in professional teaching practice, in terms of communication and presentation tools. 2) Digitally based pedagogical instructional formats are rarely used. A successful integration of media requires teachers to have (3) personal traits such as an extrovert, intrinsically motivated personality, time resources, suitable technical equipment and administrative support. Teachers moreover need (4) methodological and technical, but also pedagogical-didactic competencies for media use in instructional practice as well as competencies to use the enhanced possibilities of communication and collaboration. The current research debate has discussed 
(5) situated digitally supported long-term trainings on media technical foundations, accompanied by phases of reflection and coaching and an exchange among peers.

The mere availability of media does not present a sufficient condition of media integration into instructional practice. An improvement of teaching and learning practices can only be expected if besides technical and pedagogical-didactic support systems for teachers, teacher professionalization and a change of roles, the need is also recognized to adapt organizational procedures. These processes need to be interlinked and strategically located in a school development process that requires leadership. In this regard, a central position is assigned to school principals. They can initiate and govern school developmental processes and changes. Via their professional identity, they contribute to a vision how schools should be shaped in a digital world. They act within a system of different aspects such as school development, actors and conditions and they co-ordinate a complex interplay of top-down and bottom-up processes.

We can summarize that the rapid process of digital transformation requires a change of narrative linked to the school as a system. This is about understanding change and transformation as an integral part of school. Since educational reform at the beginning of the 19th Century that is linked to Wilhelm von Humboldt, the school system has been characterized by a high degree of stability. In the context of digitizing, change and transformation need to be shaped in a participative way and strategically implemented - and this needs to be integrated into school culture as a criterion of quality.

\section{REFERENCES}

Booth, A., Sutton, A. \& Papaioannou, D., 2016. Systematic Approaches to a Successful Literature Review. SAGE, Los Angeles.

Bundesministerium für Bildung und Forschung (BMBF), 2021. Zusatz-Verwaltungsvereinbarung „Leihgeräte für Lehrkräfte“ zum Digitalpakt Schule 2019 bis 2024 vom 27. Januar 2021, Bundesanzeiger vom 18.02.2021. https://www.bmbf.de/foerderungen/bekanntmachung-3388.html

Burow, O., 2018. Schulleitung in Zeiten von Globalisierung und Digitalisierung. In Schule 2030plus. Back to the future - Gestalten Sie die Zukunft Ihrer Schule. Sonderausgabe für Carl-Link-Abonnenten.Carl Link, Kronach, pp. 71-83.

Gouëdard, P., Pont, B. \& Viennet, R., 2020. Education responses to Covid-19: Implementing a way forward. OECD Working Paper No. 224. https://doi.org/10.1787/19939019.

Grant, M.J. \& Booth, A., 2009. A typology of reviews. Health information and libraries journal, 26 (2), pp. 91-108. https://doi.org/10.1111/j.1471-1842.2009.00848.x

Kerres, M., 2020. Bildung in der digitalen Welt: Über Wirkungsannahmen und die soziale Konstruktion des Digitalen. MedienPädagogik. [preprint]. https://www.medienpaed.com/. https://doi.org/10.21240/mpaed/jb17/2020.04.24.X

Kerres, M. 2021. Didaktik. Lernangebote gestalten. Waxmann. Münster/New York (in press).

Kleinert, C., Bächmann, A.-C., Schulz, B., Vicari, B. \& Ehlert, M., 2021. Für wen brachte Corona einen Digitalisierungsschub? Veränderungen in der Nutzung digitaler Technologien während der COVID-19-Pandemie. NEPS Corona \& Bildung. Aktuelle Auswertungen des Nationalen Bildungspanels. Bericht Nr. 6. pp. 1-6. https://www.lifbi.de/Portals/13/Corona/NEPS_Corona-und-Bildung_Bericht_6-

Digitalisierung.pdf?ver=yjR73zOPp4QhA6Q4U8eAvg\%3d\%3d

Leibniz-Institut für Bildungsverläufe (LIfBi)., 2020. Corona-bedingte Schulschließungen - Und nun funktioniert alles digital...? NEPS Corona \& Bildung | Bericht Nr. 1, pp. 1-7. https://www.lifbi.de/Portals/13/Corona/NEPS_Coronaund-Bildung_Bericht_1-Schule.pdf.

Rolff, H.-G. \& Thünken, U., 2020. Digital gestütztes Lernen. Praxisbeispiele für eine zeitgemäße Schulentwicklung., Beltz, Weinheim.

Sipilä, K., 2014. Educational Use of Information and Communications Technology: Teachers' Perspective. Technology, Pedagogy and Education, 23(2), pp. 225-241. https://doi.org/10.1080/1475939X.2013.813407.

Wilmers, A., Anda, C., Keller, C. \& Rittberger, M. (eds.)., 2020. Bildung im digitalen Wandel. Die Bedeutung für das pädagogische Personal und für die Aus- und Fortbildung. Waxmann Verlag, Münster. https://doi.org/10.31244/978383099199

Wilmers, A., Achenbach, M. \& Keller, C. (eds)., 2021, in press. Bildung im digitalen Wandel: Organisationsentwicklung in Bildungseinrichtungen. Waxmann Verlag, Münster.

Zhao, Y., 2020. COVID-19 as a catalyst for educational change. Prospects, 49, pp. 29-33. https://doi.org./10.1007/s1125020-09477-y 